\title{
Ernesto Cardenal: ¿Profeta en su tierra?
}

Erick Aguirre Aragón*

* Periodista de El Nuevo Diario, Kilómetro 4 Carretera Norte. Managua. E-mail: eaguirre@elnuevodiario.com.ni

\section{Recibido: septiembre de 2006 / Aceptado: octubre de 2006}

EN UN CONTEXTO HISTÓRICO Y SOCIAL COMO EL DE LA CENTROAMÉRICA contemporánea, en el que los nuevos escritores parecen exagerar en su preferencia por una poesía "no contaminada por la política"; más allá de cualquier preferencia temática o estilística entre las nuevas generaciones de poetas, sería imperdonable no detenerse a admirar el emblema histórico que tanto la figura como la obra poética de Ernesto Cardenal representan para Nicaragua y para todo el continente americano.

Esteta de la simpleza, la especificación y el detalle como recurso estilístico para reforzar la memoria histórica y fortalecer una idea emancipadora de la identidad hispanoamericana, Cardenal y su obra suscitaron una profusa polémica que aún sobrevive en medio de los debates sobre el quehacer poético en Nicaragua. Mientras muchos escritores rechazan la influencia de su poética, otros la asumen (a veces hasta involuntariamente) como parte de una tradición insoslayable. Aunque, a la larga, lo más probable es que en la riqueza intelectual de tal bifurcación, o en su sincretismo, se delineará el futuro camino de las nuevas generaciones poéticas nicaragüenses.

La de Cardenal ha sido una de las voces más altas de la poesía americana de nuestro tiempo. Desde la participación en conspiraciones políticas contra la dictadura de la familia Somoza, pasando por la evolución de un intelectual militante, su vida y su obra constituyen una de las principales aventuras históricas de la lírica y la épica nicaragüenses. Este ensayo valora, con suficiente balance y objetividad, la importancia de esa obra y de esa trayectoria.

Palabras clave: Cardenal, Ernesto-crítica e interpretación / Cardenal, Ernestopoesías / poesía-valoración

Según el escritor Jorge Luis Borges, la mayor imperfección del intelecto humano es su carácter sucesivo y lineal, su encadenación al pasado y al presente, su desdichado y caprichoso idilio con la historia. De acuerdo a esta provocadora idea, la consagración al futuro, a la que por ejemplo apuestan los artistas y poetas, no sería más que un acto de cobardía, por tanto, a los seres que depositan sus esperanzas en las justas recompensas de la posteridad, no les quedaría más que resignarse a las estériles y tortuosas incertidumbres del tiempo. En un breve ensayo sobre el poeta francés Guillermo Apollinare, el polémico 
autor argentino estimaba, con enorme escepticismo, que el valor general de la obra poética del francés le parecía mucho más documental que estético: "La visitamos para recuperar el sabor de la poesía moderna de los primeros decenios de nuestro siglo", escribió Borges (1986: 219) con sorprendente desdén. Sin embargo, compartiendo o no tales boutades, finalmente no podemos dejar de pensar que poesía, historia y memoria son como tres hermanas que no siempre están de acuerdo, y en una Hispanoamérica plagada de profundas pasiones políticas, nunca hará falta alguien que esté dispuesto a confrontarlas.

La exagerada admiración por lo elegante y lo relativamente extraño de la poesía modernista, incluso la pirotecnia verbal y las excentricidades de los vanguardismos europeos, por ejemplo, pudieron haber marcado desde los inicios del siglo XX a un buen número de poetas hispanoamericanos contemporáneos; pero la excepción a este nada extraño fenómeno quizás pudo haber sido Nicaragua, donde la influencia de la llamada New Poetry estadounidense en los más importantes poetas de vanguardia y post-vanguardia fue mucho más importante que otros movimientos literarios como el surrealismo. Sin embargo, después de transcurrido casi un siglo, la persistencia de esa influencia y las connotaciones histórico-políticas que algunos escritores le agregaron, parecen más bien haber provocado cierta aversión o desdén (parecido al de Borges por Apollinare) por parte de muchos autores jóvenes hacia el llamado "exteriorismo" vanguardista nicaragüense, cuyo influjo se extendió a lo largo del siglo y actualmente tiene como representante más emblemático al poeta y sacerdote Ernesto Cardenal, una de las figuras poéticas más descollantes o célebres con que cuenta Nicaragua después de Rubén Darío.

En realidad, la indiferencia de buena parte de la generación posterior al declive de la revolución sandinista en Nicaragua, hacia el tipo de poesía representado por Cardenal, posiblemente obedezca no sólo a su constante abordaje de los temas históricos, sociales y políticos, que cada vez entusiasman menos a las escépticas generaciones de post-guerra en Centroamérica, sino también a su naturaleza "antipoética”, en el sentido de una aventurada regresión hacia formas de enunciación simples, directas, sin abundancia de retórica, así como al ex profeso alejamiento de la metaforización y de las abstracciones conceptuales en la poesía de Cardenal, quien recurre sobre todo a los efectos imprevistos del coloquialismo y de la jerga oral de las calles o de la crónica periodística en su proceso de producción textual.

En un contexto histórico y social como el de la Centroamérica contemporánea, los nuevos grupos de escritores nicaragüenses parecen exagerar en su preferencia por una poesía "menos contaminada de política" que la de Cardenal. Sin embargo, más allá de cualquier preferencia temática o estilística entre las nuevas generaciones de poetas nicaragüenses e hispanoamericanos, frente a la figura de Cardenal sería imperdonable no detenerse a admirar el emblema histórico que tanto su figura como su obra poética representan para Nicaragua y para todo el continente americano. La fusión deliberada, hábil y persistente de historia, religión, política, ciencia y misticismo, constituyen a la larga un proceso dinámico de contradicción y armonía, asimilación y rechazo que hoy el mundo conoce como la vida y la obra poética de Ernesto Cardenal.

Nacido en 1925 en la ciudad nicaragüense de Granada, Cardenal hizo sus primeros estudios 
con los sacerdotes jesuitas del colegio Centroamérica de esa misma ciudad, para luego viajar a México, donde cursó Filosofía y Letras en la Universidad Nacional Autónoma. En 1954, de vuelta en Nicaragua, participó en el proceso inicial de una conspiración político-militar contra el dictador Anastasio Somoza, que al final fue cruelmente aplastada. Después hizo estudios de doctorado en la Universidad de Columbia, en Nueva York. Más tarde ingresó al monasterio trapense de Gethsemaní, en Kentucky, Estados Unidos, donde fue discípulo del conocido escritor contemplativo Thomas Merton ${ }^{1}$.

Durante los primeros años de la década sesenta Cardenal permaneció en un monasterio de Cuernavaca, México; luego se trasladó a Colombia, donde se ordenó como sacerdote. En 1966 fundó en Nicaragua la comunidad cristiana de Solentiname, donde convivió con pescadores y campesinos que luego se integrarían a la guerrilla sandinista. En 1977 la comunidad fue clausurada por el régimen somocista y desde entonces, hasta el derrocamiento de la dictadura en 1979, Cardenal permaneció en el exilio. Luego, de 1980 a 1989, fue ministro de cultura del gobierno sandinista. Actualmente es promotor de la pintura primitivista nicaragüense y directivo de la Asociación Nicaragüense de Escritores.

\section{Profeta y vocero de la revolución}

Auto-considerado profeta de la revolución sandinista en el mundo y en su propia tierra, según sus propias palabras ${ }^{2}$; esteta de la simpleza, la especificación y el detalle como recurso estilístico para reforzar la memoria histórica y fortalecer una idea pretendidamente emancipadora de la identidad hispanoamericana, Cardenal parecía empeñado --durante el tiempo en que el sandinismo estuvo en el poder en Nicaragua (1979-1990)-- en multiplicar su estilo poético y sus reglas formales entre las nuevas generaciones; esfuerzo que encontró suficiente eco, sobre todo en aquellos escritores que siempre creyeron, no sin cierta razón, en los presuntos beneficios de una escuela cardenaleana en Nicaragua.

Sin detenernos a discurrir sobre la validez o invalidez de este argumento, finalmente se habrá de reconocer la obvia existencia y aún la influencia y fructificación de su escuela poética, al menos en un considerable número de nuevos escritores, sin menoscabo de tantos otros jóvenes que acogen con entusiasmo otros estilos y otras opciones técnicas y temáticas. Aunque a la larga, lo más probable es que en la riqueza intelectual de tal bifurcación o en su sincretismo, se delineará quizás el futuro camino de las nuevas generaciones poéticas en Nicaragua.

La de Cardenal ha sido sin duda una de las voces más altas de la poesía americana de nuestro tiempo. Desde la participación en conspiraciones políticas contra la dictadura de la familia Somoza, pasando por la evolución de un intelectual militante, su vida y su obra constituyen una de las principales aventuras históricas de la lírica y la épica nicaragüenses. En su obra supo fraguar el epigrama amoroso, preludio de su evolución mística y poética; la parodia de los salmos bíblicos que clamaban frente al tiempo oscuro de la opresión; la exploración del misterio cosmogónico y el testimonio del tiempo encendido de toda una época de lucha. Con todo, lo cierto es que no pocas generaciones en Nicaragua tendrán que aceptar ante la historia el orgullo o la incomodidad (según sea el caso) de haber compartido estos tiempos con una figura poética de enormes proporciones, que ha logrado edificar una 
voz propia en la poesía hispanoamericana, y que le dio esa voz a un proyecto histórico de profundas repercusiones sociales como fue la revolución sandinista.

La de Cardenal es también una delas voces más controversiales en la poesía hispanoamericana de la segunda mitad del siglo XX. Tanto su vida como su obra están profundamente imbricadas con el devenir de la historia política centroamericana de los últimos tiempos. Sin embargo, tal conjugación vida-obra (en el sentido "dialéctico-materialista" que él mismo habría de exigir a sus exégetas), no sólo por las razones políticas evidentes en su producción poética, sino por la radicalización y "toma de conciencia social" que dieron sentido a mucha de la literatura del istmo centroamericano en las últimas décadas del siglo XX, presenta en realidad ciertas contradicciones que, luego de un estudio minucioso, no harían en realidad tan difícil la tarea de desvincular un poco su poética de su praxis.

No es casual que en sus memorias Cardenal reconstruya los recuerdos de infancia, adolescencia y juventud, haciendo énfasis en sus primeras impresiones de la historia y la literatura nicaragüenses y de sus principales personajes (entre ellos los inevitables Rubén Darío y Augusto C. Sandino); lo mismo que en sus primeras dudas vocacionales, religiosas, amorosas o existenciales. En los primeros trechos descritos de su propia vida se revela también la influencia definitiva que en él tendrían sus primeros viajes a México, Nueva York, España y Francia, así como su vida de claustro en el monasterio trapense de Gethsemaní, donde conoció a Thomas Merton, quien habría de convertirse en su primer y más influyente maestro espiritual.

Significativamente, Cardenal narra los primeros años de su vida con una prosa de intención testimonial, plagada de giros orales que indefectiblemente recuerdan sus máximas poéticas y las tendencias más pronunciadas de su escuela estética, que como dijimos estaba profundamente nutrida del realismo de la Nueva Poesía norteamericana del siglo veinte. Por otra parte, la cita de San Lucas a que recurre para el epígrafe del primer tomo de la edición nicaragüense de sus memorias (2001): "El que pierda su Vida por mí, la salvará", encuentra su lógica en las primeras páginas del libro, y posteriormente habrá de encontrarla plenamente en los capítulos concluyentes.

En una entrevista de 1991 pregunté a Cardenal si pensaba escribir sus memorias. Aunque entonces contestó afirmativamente3 (y seguramente ya empezaba a escribirlas), también reconoció no sentirse muy apto para la introspección. Sin embargo, se atrevió a adelantar sutilmente lo que hoy es perceptible en los voluminosos tomos de sus memorias. "A lo mejor haga algunos pasajes rememorativos pero no sería un libro ajustado cronológicamente al orden de mi vida”, declaró, confirmando con antelación el "orden” de alguna forma novelesco con que las ha organizado y editado. Lo cierto es que desde las primeras páginas de sus memorias se percibe el empeño del poeta por entregar su vida a Dios, o a algo "terrenal" que lo simbolice, y en ese acto, con ese hecho, hacerla fructífera. Los capítulos que se refieren a su heterogénea y activa experiencia política, significativamente vienen a ser los más intensos, y por supuesto los más controversiales, sobre todo por dos axiomas ideológicos constantes en su vida: la relación cristianismo-revolución y la relación literatura-revolución.

A tono con su auto-proclamación de profeta de la revolución sandinista, Cardenal asume 
casi como un dogma la elección humana y revolucionaria del poeta y militante del Frente Sandinista de Liberación Nacional (FSLN) Leonel Rugama, muerto en combate (a los 19 años de edad) contra la guardia de Anastasio Somoza en 1969, y que, al menos textualmente, Cardenal asume para sí: "No debe haber una sola palabra, en poesía, que el poeta no respalde con su acción. Sólo cantar la revolución y no estar involucrado en ella, no es muy consecuente. Al menos para mí, no". ${ }^{4}$ Sin embargo, en este punto de su discurso es donde surgen las primeras contradicciones, porque Rugama, de acuerdo a sus propios testimonios y ensayos publicados póstumamente, no veía o se planteaba la revolución "como un simple escritor", sino que eligió convertirse en militante político-militar, en combatiente revolucionario, renunciando con ello, al menos "temporalmente", a su condición de intelectual, escritor o poeta.

Según el ex miembro del directorio nacional del FSLN, Jaime Wheelock, quien prologó la primera edición del único libro escrito por Rugama, éste insistía en que había que concentrarse más "en el aspecto principal de la lucha”, que era justamente la lucha armada contra Somoza. "Resolver la cuestión del poder, y así resolver la cuestión de la cultura”, era el axioma con que a Wheelock le agradaba coincidir al presentar póstumamente la obra del joven poeta sacrificado. En Rugama, afirma Wheelock (1980: III), "se integran con plena armonía el pensamiento y la acción; la moral con la cultura; la realidad con la belleza... la revolución”. No había, pues, tiempo para dedicarse a forjar una carrera literaria. Aunque lo que sí es claro, al menos ahora que podemos examinar en perspectiva los avatares en la vida del poeta trapense, es que él sí tuvo tiempo de hacerlo, incluso en los momentos de pleno compromiso militante con el sandinismo; circunstancia posiblemente relacionada con el complaciente "tratamiento político" que habrían optado por dar a Cardenal los dirigentes sandinistas en la década de los setentas.

Este tratamiento de cierta adulación, algo así como la seducción y conquista de una vedette para propósitos políticos, también fue característico por parte de la revolución cubana hacia Cardenal, a quien los guerrilleros centroamericanos y la burocracia socialista de la isla veían como un profeta o "santón" iluminado que, para su suerte, se identificaba con su causa y que a cambio no ocasionaba más molestias que las de insistir en su religiosidad popular y en ideas pacifistas que después ellos mismos le ayudarían a disipar. Incluso existe un breve y complejo periodo de la relación inicial de Cardenal con la revolución cubana que, por razones hasta ahora sólo inmersas en la especulación y la duda, no se registra con la suficiente veracidad o precisión en las memorias del propio Cardenal: en 1970, durante la primera visita del poeta a La Habana, invitado a ser jurado del Premio Casa de Las Américas de ese año, el escritor salvadoreño Roque Dalton fue incluso víctima del desprecio y la ingratitud de los cubanos por situarse en medio de este proceso de seducción y conquista de Cardenal para la "causa revolucionaria".

De hecho, al igual que Dalton en El Salvador, Leonel Rugama se integró a la revolución nicaragüense casi como un combatiente de línea, en cambio Cardenal lo hizo como una especie de "vocero poético", como un elemento de apoyo a la propaganda. Aunque también se debe reconocer su participación indirecta, antes de incorporarse al sandinismo, en una sangrienta y fracasada rebelión anti-somocista en abril de 1954 (en la que participaron oficiales jóvenes del ejército de Somoza provenientes de familias adineradas ligadas por 
prosapia y amistad a la propia familia de Cardenal); así como su apoyo propagandístico a la lucha armada del FSLN y la permanente inclinación de compromiso social en una extensísima parte de su corpus poético.

En cuanto al axioma cristianismo-revolución (estrechamente relacionado con su producción poética y su militancia política), sus memorias evidencian el tormento interior de la duda que atenazó su conciencia por muchísimo tiempo: la renuncia a una vida "normal" o a una carrera literaria prometedora, por su obsesión de enlazar su vida a Dios, ya sea como religioso o como revolucionario. En cierto aspecto, el caso Cardenal tiene cierta semejanza con el del cura rebelde colombiano Camilo Torres. Como Cardenal en Nicaragua, Torres estuvo vinculado por lazos familiares a la oligarquía colombiana, circunstancia que de cierta manera enaltece la decisión de ambos de entregarse, tanto al sacerdocio como a la lucha por la redención popular, aunque las circunstancias específicas (participación directa en las tareas militantes de la clandestinidad y en el combate revolucionario) que diferencian a Cardenal de un Roque Dalton en El Salvador, un Rugama en Nicaragua, un Javier Heraud en Perú o un Otto René Castillo en Guatemala, por ejemplo, lo diferencian también de Camilo Torres.

Nacido en el seno de una familia de la oligarquía conservadora de Nicaragua, Cardenal está registrado por la historiografía nicaragüense entre la generación de poetas de la década cuarenta. Sin embargo, la crítica hispanoamericana ${ }^{6}$ generalmente lo presenta como uno de los más emblemáticos poetas de los años sesentas, época en que la historia política del continente volvió a ponerse en marcha con la pujante irrupción juvenil en todos los órdenes, la influencia inicial de la revolución cubana y el talento literario de poetas como, entre otros muchos, Antonio Cisneros, José Emilio Pacheco, Enrique Lihn, o el mismo Dalton y Castillo en Centroamérica, a quienes, en promedio general, Cardenal los sobrepasa en edad en aproximadamente unos veinte años.

Las circunstacias histórico-sociales (la lucha revolucionaria del sandinismo y sus primeras acciones espectaculares desde 1970 hasta la victoria insurreccional de 1979) y la subrayada actitud política, tanto de la figura como de la poesía cardenaleana, le dieron fama y proyectaron su obra a niveles internacionales como a ningún otro poeta nicaragüense desde Rubén Darío. De ahí la importancia y las manifestaciones de interés mundial sobre su obra poética, así como por la auto-revisión personal retrospectiva que podemos apreciar en sus memorias. Pero es en realidad el axioma dinámico del contenido y la forma (conjunción poética y política) de la poesía de Cardenal --inicialmente influenciado por el Neruda de los 20 poemas, los epigramas latinos y el realismo norteamericano--, lo que le proporcionó en una segunda etapa de su obra, el relieve que hoy posee; a partir, por supuesto, de obras políticamente comprometidas como el Canto Nacional, dedicado al FSLN.

Este brillo excesivo de Cardenal produjo simultáneamente, y como refracción comprensible, la opacidad (al nivel hispanoamericano) de la sumamente talentosa generación poética nicaragüense de los años sesentas, y también de los no menos talentosos y brillantes compañeros de su propia generación: Carlos Martínez Rivas y Ernesto Mejía Sánchez, quienes, sin embargo, desde el inicio de su obra poética y casi en sordina, prefiguraron el tono de irreverencia política y cuestionamiento ético-social que caracterizaría a la mayoría 
de la poesía nicaragüense y centroamericana de la segunda mitad del siglo XX.

Probablemente, la extensa y entusiasta recepción de que ha gozado y sigue gozando Cardenal, sobre todo fuera del área hispanoamericana, se deba en parte a que las constantes temáticas de su obra coinciden con las variadas inquietudes colectivas de las juventudes del llamado Primer Mundo en las últimas décadas del siglo XX (hippies, ecologistas, renovadores teológicos, movimientos de solidaridad con el Tercer Mundo, etcétera). Aunque lo cierto es que la confluencia de sus recurrencias temáticas, unidas a la singularidad de su tono coloquial en la escritura y al hábil montaje de textos de la más diversa procedencia en el espacio poético, constituyan el fundamento principal de su extraordinaria celebridad. De manera pues que la obra de Cardenal corrió con más que buena suerte en cuanto a su proyección y divulgación en el mundo de habla hispana, es decir, disfrutó del caprichoso destino de sobresalir y seguir sobresaliendo entre más de dos o tres generaciones posteriores en Nicaragua y aun en el continente americano.

\section{Una obra vasta y coherente}

Aunque sus primeras obras conocidas, La ciudad deshabitada (1946) y Proclama del conquistador (1947), son visiblemente diferentes a otras posteriores que le dieron celebridad, de alguna forma poseen cierto hilo de coherencia que las conecta con la esencia de todo su corpus poético. Si bien La ciudad deshabitada evidencia mucha influencia del chileno Pablo Neruda, Proclama del conquistador, su primer poema épico de largo aliento, es una incursión en la historia que intentaba recrear intertextualmente las crónicas históricas de los conquistadores para elevarlas a categoría poética, lo cual se constituiría más tarde en uno de los recursos que explotaría con evidente talento en sus grandes poemas épico-históricos.

Posteriormente, su poema Hora O (1960) preludiaba también su permanente incursión en el tema político-social, que se desarrollaría casi inmediatamente después en su libro Epigramas (1961), en el que se ejercitó traduciendo los epigramas de Catulo y Marcial, agregando un buen número de poemas propios. En Gethsemany, Ky (1960) recrea su experiencia monástica incorporando con mayor propiedad el estilo sencillo, directo, que caracterizaría en adelante a casi toda su obra. El tema místico-religioso de Gethsemany, $K y$, también pasaría a formar parte del núcleo dominante alrededor del cual gravita toda su poesía. Es un tema también predominante en Vida en el amor (1961) y Salmos (1964) donde la parodia de los salmos bíblicos obedece a la intención política de conectarlos hábilmente con la realidad moderna, subrayando su sentido de protesta y solidaridad ante la injusticia; algo que prosiguió y llevó a un punto extraordinario de intensidad poética en Oración por Marilyn Monroe y otros poemas (1965), en el que cuestiona la deshumanización de la sociedad de consumo capitalista.

En El estrecho dudoso (1966) y Homenaje a los indios americanos (1969) retoma su intento inicial de recuperar humanísticamente el ámbito indígena y sus valores extinguidos y suplantados por la conquista y la colonia en América. En Coplas a la muerte de Merton (1970), homenaje a su maestro, retoma el tema místico-religioso, y en Oráculo sobre Managua y Canto Nacional (1973), lo hace con el tema socio-político, recurriendo a la crónica, al 
collage y a la superposición de imágenes y contextos históricos que utilizaría eventualmente en sus mejores poemas. Luego en Quetzalcóatl (1986) retoma a su vez el tema indígena mesoamericano, estableciendo conexiones, a través de la hábil manipulación textual de la representación visual de hechos históricos emblemáticos, con la contemporaneidad política y social. Previamente había publicado Vuelos de victoria (1985), que fue incorporado más tarde a su culminante y ambicioso Cántico cósmico (1989), que sería seguido por su más reciente libro de poemas publicado en 1993: El telescópio en la noche oscura, una especie de adéndum o epílogo del Cántico, donde el poeta se apropia simbólicamente, en un sentido místico, del instrumento científico de exploración del cosmos para utilizarlo como una metáfora del alma humana contemplando el universo.

En los últimos años diversos críticos han reparado con especial atención en el místico y especulativo Cántico cósmico, que a ojos de sus más enconados detractores no pasa de ser un collage de información científica, aunque para algunos de sus exégetas hispanoamericanos como Jorge Román Lagunas (2000) es la obra culminante, de alcances aún insospechados, del poeta Cardenal. Para Román Lagunas el Cántico es --como resultado de la búsqueda de espacios nuevos para la poesía-- una "profanación" poética no sólo de la historia y de la teología, sino también de la ciencia; una amalgama poética de cosmogonía y cosmología; un intento de explicación poética tanto del origen del universo como de las leyes generales que rigen al mundo físico. Algo que, tanto para Román Lagunas como para Luce López Baralt (2003) debería llamar la atención de las nuevas generaciones.

Lagunas (2000:203) coincide con José Coronel Urtecho en apreciar el Cántico como una representación gráfico-poética del universo, "como las fotos de los astrónomos, pero en términos poéticos". Según Lagunas, Cardenal comete la "herejía” de sacar la poesía al espacio y celebrar épicamente, pero en concordancia con las leyes de la evolución astrofísica, la armonía cósmica del universo. En síntesis, una profetización de la ciencia y una cientifización de la poesía, para las cuales, según Román Lagunas, la crítica aún no está preparada.

Sin embargo, para Jorge Eduardo Arellano (1997: 229), se trata de una obra magna en su concepción, pero “desigual y saturada de verbalización pedestre”. Según Arellano (1997: 230) el Cántico es una obra "ideológicamente residual (...) casi ilegible, que no supera el maniqueísmo fanático ni el exceso de sus recursos". En tanto, el crítico suizo Gustav Siebenmann, aunque reconoce la adhesión de esta ambiciosa obra a una tradición de renovación constante, característica de la poesía latinoamericana del siglo XX, subraya su reincidencia formal en "los extensos ciclos épico-líricos" de la mencionada tradición poética latinoamericana, y lamenta que su "dispersión” le impida unidad temática y posibilidad de síntesis. Sin embargo, Siebenman reconoce la audacia de Cardenal al tratar de construir una síntesis poética de religión, naturaleza e historia, bajo la evidente influencia de las teorías evolucionistas de Teilhard de Chardin (Siebenmann, 1997: 355).

\section{Indigenismo y crisis de representación}

Por otra parte, aunque las poesías llamadas épicas de Cardenal -fundamentalmente $E l$ estrecho dudoso y Homenaje a los Indios Americanos - constituyen indudables testimonios 
histórico-literarios acerca de la vigencia del pasado precolonial y colonial en la realidad y la cultura de la mesoamérica contemporánea; sus formas de representación también son sumamente ambiciosas, aunque en este caso persisten en la sobredimensión simbólica del mundo indígena como una herencia esplendorosa y abolida, aunque paradigmática y refractaria de las diversas formas de descomposición social en la modernidad.

El estrecho dudoso es un extenso poema de temática histórica cuya evidente ambición es reconstruir textualmente el periodo de descubrimiento y conquista de Centroamérica por parte del imperio español. Según Iván Uriarte (2000: 213), la tentativa fundamental de este poema es la objetividad histórica, evidente no sólo en el procedimiento intertextual de transformación (sin alteración en el contenido) de los textos incorporados al poema, sino también en las relativamente pocas intervenciones retóricas en el discurso. Las escasas intervenciones son puntuales, y sólo se producen cuando parece necesario desencadenar similitudes entre el pasado y el presente, obligándonos a leer el texto desde una perspectiva contemporánea.

Uriarte destaca el recurso cardenaleano de la trasposición literal, que le permite revitalizar y reactualizar textos de importancia no sólo histórica sino literaria, que no han sido valorados debidamente por la historiografía. También destaca el acierto literario de suspender el texto entre dos códigos tonales: uno actualizado por el trabajo de transformación para hacer accesible el texto, y otro que conserva (casi como una copia facsimilar) su fuerza original, manteniendo así la vitalidad de los signos en el tiempo. "Más que documental -apunta Uriarte- es una mise en scene de las fuerzas desencadenadas de la historia”.

Pero en Homenaje a los indios americanos, Uriarte (2000: 181-183) observa más bien una tendencia de Cardenal a buscar en el pasado prehispánico un modelo de sociedad que pueda ser contrapuesto a los modelos de explotación imperantes en la Centroamérica contemporánea. Inspirado y apoyado en los descubrimientos arqueológicos y en los estudios antropológicos modernos, Cardenal parece dispuesto a identificar en el pasado pre-colonial mesoamericano, los cimientos de la cultura centroamericana contemporánea. En ese pasado "misterioso" y remoto, Cardenal parece haber encontrado el modelo económico y social a seguir en la contemporaneidad.

\author{
Otro Renacimiento ("Periodo clásico") \\ cambia la forma de la vasija y el dibujo en ellas \\ cambia la arquitectura (...) \\ ¿Ciudades? Sí \\ pero ciudades sagradas \\ no Commercial Centers \\ sino Centros Ceremoniales, Ceremonials Centers
}

las filas de estelas y estelas, no neón, no anuncios comerciales

(sus anuncios: ipoemas en piedras!)

(Homenaje a los indios americanos)

Su propósito parece ser la incorporación del indio a la utopía socialista de la nueva sociedad 
y el "hombre nuevo", estableciendo un paradigma aparentemente anacrónico, en el cual la figura abolida del indio representa e idealiza el futuro y la sociedad futura. Aunque, según Jorge Eduardo Arellano (1996: 227), debido a que Cardenal supuestamente adopta el pensamiento comunal ${ }^{7}$ (según el cual es necesario asimilar los elementos positivos de la civilización moderna, conservando aquellos más valiosos de las sociedades indígenas), esta idealización finalmente no le permite realizar una condena absoluta de la sociedad contemporánea.

En lo relacionado a procedimientos textuales, en los poemas de Homenaje Uriarte también observa una característica que considera generalizada en la poesía de Cardenal y que también lo identifica con vanguardistas nicaragüenses como Pablo Antonio Cuadra, cuya visión poética del mestizaje hispanoamericano es culturalmente mixta pero tendiente a una concepción hegemónica occidental, formalmente visible en el método interior de contraposición de imágenes y situaciones; procedimiento textual que le da a los poemas de Cardenal una estructura interior de oposiciones, evidentemente alegórica de las "contradicciones armónicas" del mestizaje indo-hispano, así como de los choques y encuentros entre ambas culturas.

Homenaje agrupa poemas en los que se hace visible una dinámica asociativa del texto que intenta vincular las distintas tradiciones y modelos socio-culturales (incluso económicos) de los grupos y civilizaciones indígenas pre-hispánicas de Norte, Centro y Sur-América. En algunos de ellos (sobre todo los relacionados al mundo maya y mesoamericano en general) Cardenal asume, al igual que Cuadra, procedimientos textuales devenidos de la narrativa como la utilización de hablantes o personajes que vienen siendo más bien máscaras asumidas por el autor para representar lo más eficazmente posible el ámbito prehispánico en Centroamérica.

El autor/personaje del poema asume el papel de profeta, decodificador de los signos y previsor de los ciclos temporales que regían la vida y la noción del mundo prehispánico mesoamericano, especialmente el maya. Cardenal asume, a través de alter-egos, la función profética arraigada profundamente en la tradición indígena mesoamericana, intenta encarnarla y trasladarla adecuadamente a la contemporaneidad, agregándole además, a través de símiles, sutiles comparaciones, metáforas y yuxtaposiciones textualmente armónicas, elementos clave de la tradición profética hebrea desarrollada en el Antiguo Testamento.

Desde un ámbito social y cultural capaz de producir textos con pretensión de trascendencia, es decir, desde la letra y el lenguaje como instrumentos culturalmente hegemónicos heredados de occidente, Cardenal se auto-asigna el papel de "vocero del pueblo", y a través de su máscara o hablante poético se siente capaz de conocer a profundidad y asumir como suyos el universo y la visión del hombre prehispánico mesoamericano. Su procedimiento textual consiste, como lo reconoce incluso su exégeta Eduardo F. Elías (1999: 195), en servirse de los nombres indígenas asignados a los ciclos del calendario maya, "modificando antiguas profecías halladas en los libros históricos (como el Chilam Balam) y aplicándolas a la vida contemporánea de Latinoamérica". 
modernos y su proyección pasado-presente en la teleología poética cardenaleana, sea lo que distinga su aporte más característico a la poesía nicaragüense e hispanoamericana de temática indígena; pero para "críticos más rigurosos", citados por el mismo Arellano (1996: 228), el intento de Cardenal contiene un abuso en el tratamiento de las formas mitológicas, al punto de hacerlas "menos interesantes que las fuentes originales". "Prosaísmo, mitología en grandes dosis, maniqueísmo, utopía político-social, elementalismo expresivo de algunos otros ingredientes de menor consideración, no logran formalizar un auténtico poema”. ${ }^{\circ}$

Por su parte, el crítico estadounidense Steven F. White también ha identificado y se ha ocupado del amplio retrato de la figura indígena en la poesía de Cardenal, pero lo percibe, inicialmente, como fruto del aprendizaje espiritual del poeta nicaragüense con Thomas Merton y su labor investigadora de la poesía "primitiva" amerindia. Según White, los diversos aspectos de las sociedades indígenas norteamericanas representadas en su poesía, constituyeron un modelo ético novedoso y atractivo para Cardenal, sobre todo las características de espiritualidad, anti-materialismo y agrarismo que de acuerdo a la apropiación ético-poética del nicaragüense, constituirían la base para una probable definición de una responsabilidad moral precedente a los cambios sociales. (White, 1992: 212)

Pero la proyección de la voluntad ético-indigenista (y subrayadamente histórico-política) en la poesía de Cardenal, se extiende con mayor profundidad e identificación simbólica hacia toda Mesoamérica y aun a los antiguos imperios y civilizaciones pre-coloniales en el sur americano. El mismo White (1996: 212) reconoce que, desde Proclama del conquistador, uno de los primeros poemas de Cardenal, puede definirse un punto de partida de la temática histórica que irradiará casi toda la obra cardenaleana. Algo así como el génesis de lo que luego se convertiría en el principal hito ético-temporal de su poesía, en la que será frecuente la utilización del pasado en yuxtaposición constante con el presente, como búsqueda de un efecto estético que dé fundamento, en la contemporaneidad, a las antiguas profecías.

Una de las características de la poesía histórica y/o indigenista de Cardenal, que White asocia con el procedimiento poundeano del "enmascaramiento", es la utilización de hablantes poéticos, personajes o narradores idóneos que le permitan evocar y conjurar el pasado desde el presente, o bien, desde un espacio atemporal construido en la propia dinámica del poema. Este hablante poético es generalmente un personaje histórico y con frecuencia toma la forma de personaje-poema, en un procedimiento que, según White (1996: 227), permite a Cardenal "mantener un diálogo intenso con el pasado y manipular la historia para crear un futuro más ético".

...y Gil González con 100 hombres y 4 caballos

entró en la tierra --...y caminando yo siempre por la tierra adentro hacia el poniente metido algunas veces tan lejos de la costa

que muchas veces me hallé arrepentido

y a causa de pasar los ríos y arroyos a pie y sudando

sobrevínome una enfermedad de tullimiento en una pierna (...)

iEl Almirante de la Mar Dulce!

Gil González pide a su Magestad la merced del almirantazgo de la Mar Dulce

y de tres islas en la dicha Mar Dulce

para él y sus herederos y descendientes (...) 
Gil González y Nicaragua se sentaron junto al lago.

El conquistador con ropa de hierro,

el cacique casi desnudo.

(El estrecho dudoso)

En efecto, la relación con Ezra Pound y con el tema histórico-político no es gratuita: "ambos poetas saben perfectamente que los procesos políticos y económicos tienen el poder de condicionar todos los aspectos de la vida" (White, 1996: 223). Ambos también desarrollan un tipo de poesía concreta, objetivista ("exteriorista", según el término que en Nicaragua "acuñaron" José Coronel y el propio Cardenal), pero en el caso del nicaragüense desde referencias profundamente éticas y políticas, desde una perspectiva personal que asume toda una ética colectiva. Según White, el concretismo poético o la supresión deliberada de elementos subjetivos en la poesía de Cardenal, se basa en un lenguaje aparentemente objetivista que, pese a expresar las cosas "fuera del ser", "en el mundo externo", implica más bien la proyección de "ciertos valores íntimos (...), personales, misteriosos, urgentes" (White, 1996: 225). Esto, además del hecho relativamente teleológico que constituye el acto mismo de crear o construir un poema, implica también la voluntad subjetiva y consciente que lleva al autor a la acción de seleccionar y escoger los elementos con los cuales procederá a configurar el texto.

Pero el enmascaramiento como procedimiento poético en Cardenal permite también definir con claridad una voluntad letrada de mediación y apropiación desde una perspectiva (si bien ética y "redentorista") inevitablemente afectada por la dinámica contradictoria de alteridad que implica el hecho de la condición preponderantemente occidental en la perspectiva individual del poeta nicaragüense. Por eso, desde su primer acercamiento a la temática indígena en Proclama del conquistador, su visión está marcada, como bien señala el crítico Paul W. Borgensen Jr. ${ }^{10}$, por la de un personaje histórico que, más que simbolizar el mundo evocado, representa el encuentro de las dos razas.

En Cardenal, la apropiación del ámbito indígena toma la forma, claramente mediadora, de la máscara poética, una máscara que le permite "comunicarse" con el personaje evocado y a la vez representarlo. El mismo White (1996: 233) reconoce, refiriéndose a un poema de Homenaje, que al adoptar la máscara, el espíritu de la figura indígena resucitada parece poseer al poeta/profeta, quien se convierte en intermediario, recibiendo signos, transformándolos y transmitiéndolos en la forma de un discurso poético.

En este punto resulta fácil identificar las analogías entre Cardenal y Pablo Antonio Cuadra, tanto en lo relacionado al procedimiento textual devenido de la narrativa moderna como en lo referido al tratamiento del conflicto de alteridad indo-hispano aparentemente resuelto o "armonizado" con la identificación y potenciación del mestizaje en las alegorías textuales construidas en la obra de estos dos renombrados poetas. Ambos (Cuadra y Cardenal) trascienden por primera vez en Nicaragua, desde la perspectiva histórico-social (aunque quizás también antropológica o arqueológico-literaria), los esbozos de "realidad social indígena" que apenas habían prefigurado poetas nicaragüenses anteriores como Rubén Darío y Salomón de la Selva, o más contemporáneos como el vanguardista Joaquín Pasos. 
Sin embargo, ninguno de ellos logra eludir la ambigüedad de su perspectiva mestiza, su visión parcialmente española, parcialmente indígena, del remanente prehispánico en la realidad centroamericana contemporánea. Cardenal, desde su ánimo testimonial y de denuncia histórico-social, se coloca en una posición de mediación entre el sujeto subalterno y el poder hegemónico, dejando visible sólo parcialmente la verdadera posición subordinada y periférica del sujeto en las relaciones actuales de poder que rigen a la sociedad nicaragüense y centroamericana. En tanto que Cuadra, obsesionado quizás por su evidentemente más pronunciada naturaleza criolla-mestiza, indohispana, así como por su propia noción del mestizaje, medita constantemente acerca de la dualidad intrínseca a esa "nueva identidad" configurada en el Nuevo Mundo a partir de la conquista. Su apropiación de lo prehispánico es más dramática que épica, y tiende, por un lado a ponderar "lo nicaragüense", la idea de nacionalidad, y por otro a reforzar esa idea con la relectura y reelaboración de los mitos y códigos ideogramáticos de la cultura originaria mesoamericana.

Esta singular identificación intergeneracional entre un poeta mayor en edad (Pablo Antonio Cuadra) y quien, según la historiografía y los propios testimonios autobiográficos de Cardenal, fue por muchos años su discípulo, no deja de causar extrañeza en los críticos nicaragüenses de más recientes generaciones. Beltrán Morales (1989: 42) señala el fenómeno destacando la relación (también discípulo-maestro) de Cardenal con el también vanguardista José Coronel Urtecho, quien escribiera una extensa carta-prólogo a la primera edición de El estrecho dudoso $^{11}$, en la que, contradictoriamente al espíritu alegórico anti-dictatorial reflejado en el libro de Cardenal, condena la persistencia, en la realidad actual, de "sabotajes y calumnias" contra la conquista española, y se refiere al dictador Anastasio Somoza García como su amigo y partidario, a quien confiesa haberle servido como funcionario de gobierno. Según Morales, tales afirmaciones resultan incongruentes en el prólogo a un libro de "denuncia indigenista", escrito por el autor de otros poemas que, como Hora cero, exaltan la lucha antidictatorial y denuncian el asesinato del héroe anti-intervencionista Augusto C. Sandino, por órdenes de Somoza. "Lo lógico en este caso hubiera sido esperar un conflicto de generaciones, una violenta ruptura (...) Y lo que se perdió en riqueza polémica se ganó en unidad y armonía intergeneracionales. Que yo sepa, únicamente en Nicaragua ocurren portentos semejantes. (Morales, 1989: 42)

Pero refiriéndose específicamente a la relación Cuadra-Cardenal, Morales cree encontrar la naturaleza y origen de este "leve parentesco" (Morales, 1989: 279), en el inevitable influjo de la poesía de Ezra Pound y la constante consulta e identificación con los cronistas españoles. Aunque lo cierto es que la producción textual de ambos poetas se identifica en una teleología poética común, cuya idea central consiste en que las formas culturales del pasado pretenden finalmente convertirse en proyectos proféticos para la vida presente o futura de las sociedades centroamericanas.

Sin embargo, debido a la naturaleza textual (en el sentido de letra y lenguaje occidentales) de su proyección social, pero también a sus propios conflictos de representación, estas formas culturales suelen mostrarse revestidas de funciones meramente simbólicas cuyas significaciones, a pesar de poseer diferentes matices e incluso intenciones ideológicas aparentemente opuestas, permiten que ambos autores coincidan en el intento de justificar una ausencia (supuestamente la indígena) en la contemporaneidad, para, al mismo tiempo, 
entenderse y explicarse a sí mismos como representantes ambiguos y eventualmente contradictorios de un poder cultural hegemónico.

\section{Notas}

1 Teólogo y crítico estadounidense. Maestro de novicios en el monasterio trapense Nuestra Señora de Gethsemaní, en Kentucky, Estados Unidos, donde Cardenal decidió enclaustrarse para llevar vida religiosa en 1956.

2 Entrevista con el autor, publicada en "El Semanario", Managua, 1991.

3 Ibidem.

4 Ibidem.

5 La revista colombiana "Malpensante" publicó en su número 44 (Marzo del 2003), una carta hasta entonces inédita de Roque Dalton dirigida (en agosto de 1970) a la Dirección del Partido Comunista de Cuba, donde abunda en detalles sobre la relación del tratamiento cubano hacia Cardenal, con la renuncia del propio Dalton como funcionario de Casa de las Américas.

6 Saúl Yurkievich, en "La movediza modernidad" (Taurus, 1996) y Julio Ortega en su "Antología de la poesía hispanoamericana actual" (Siglo XXI, 1998), entre otros.

7 Nele de Kantule, citado por Arellano (1996: 227) en "Literatura nicaragüense".

8 Joaquín Marco, citado por Arellano (1996: 228).

9 Especialmente desarrollado en el libro "Personae" (1926), de Ezra Pound.

10 Citado por White (212).

11 Ediciones Cultura Hispánica. Madrid, 1966. Esta carta-prólogo también fue incluida en la edición nicaragüense de 1985, a cargo de la Editorial Nueva Nicaragua.

\section{Referencias bibliográficas}

-ARELLANO, J. E. (1994). Antología general de la poesía nicaragüense, Managua: Ediciones Distribuidora Cultural.

- (1996). Literatura Nicaragüense. Managua: Ediciones Distribuidora Cultural.

-CARDENAL, E. (1985). Homenaje a los indios americanos, Managua: Editorial Nueva Nicaragua.

- (1985). El estrecho dudoso, Managua: Editorial Nueva Nicaragua.

- (2000). Vida perdida (Memorias I), Managua: Anamá Ediciones.

- (2001). Las ínsulas extrañas (Memorias II), Managua: Anamá Ediciones.

- (2002). Los años de Granada (Memorias III), Managua: Anamá Ediciones.

- (2002). Salmos, Managua: Anamá Ediciones, $5^{\text {a }}$ edición.

- (2003). La revolución perdida (Memorias IV), Managua: Anamá Ediciones.

- (2003). El telescopio en la noche oscura, Managua: Anamá Ediciones, $4^{\mathrm{a}}$ edición.

-CERRUTTI, F. (1977). El mundo indígena en la poesía nicaragüense contemporánea, Managua: Ediciones Ciclo.

-CUADRA, P. A. (1986). El jaguar y la luna, San José: Editorial Libro Libre.

— (1986). Poemas nicaragüenses, San José: Editorial Libro Libre.

— (1986). Canciones de pájaro y señora, San José: Editorial Libro Libre.

— (1997). El Nicaragüense, Managua: Editorial Hispamer.

- (2002). El Nican Náhuat, Managua: Ediciones de la Academia Nicaragüense de la Lengua.

-FERNÁNDEZ RETAMAR, R. (1984). Para una teoría de la literatura hispanoamericana, La Habana: Editorial Pueblo y Educación.

-GONZÁLEZ, J. (2000). Antología de las crónicas de indias, Managua: Ediciones Distribuidora Cultural. 
-MC CALLISTER, R. (1999). "Pablo Antonio Cuadra y la búsqueda de una poética mitohistórica”, en Román Lagunas, J. y Mc Callister, R. (Compiladores), La literatura centroamericana como arma cultural. Guatemala: Ediciones del Centro Internacional de Literatura Centroamericana (CILCA).

-MORALES, B. (1989). Sin páginas amarillas / Malas notas, Managua: Editorial Vanguardia.

-PASOS, J. (1984). Poemas de un joven, Managua: Editorial Nueva Nicaragua.

-ROMÁN LAGUNAS, J. Y MC CALLISTER, R. (1999). La literatura centroamericana como arma cultural. Guatemala: Ediciones del Centro Internacional de Literatura Centroamericana (CILCA).

-ROMÁN LAGUNAS, J. (2000a). Visiones y revisiones de la literatura centroamericana. Guatemala: Ediciones del Centro Internacional de Literatura Centroamericana (CILCA).

— (2000b). "Lo sagrado y lo profano en la poesía de Ernesto Cardenal" en Visiones....

-SIEBENMANN, G., 1997: Poesía y poéticas del siglo XX en la América hispana y el Brasil.

Madrid: Editorial Gredos.

-URIARTA, I. (2000). La poesía de Ernesto Cardenal en el proceso social centroamericano. Managua: Ediciones del Centro Nicaragüense de Escritores (ANE-NORAD-CNE).

-WHEELOCK ROMÁN, J. (1980). "Leonel Rugama: en el gozo de la tierra prometida" en Rugama, L., Obras, S.S.E.

-WHITE, S. (1992). La poesía de Nicaragua y sus diálogos con Francia y los Estados Unidos, México D. F.: Editorial LIMUSA. Grupo Noriega Editores. 